\title{
FORMULATION OF GEL FROM GYNURA SEGETUM EXTRACT AND ITS ACTIVITY ON BURN WOUND HEALING
}

\section{ARIF BUDIMAN ${ }^{a}$, MUHARAM ${ }^{b}$, ANIDA CRISTI MAULIDA ${ }^{b}$, DIAH LIA AULIFA ${ }^{c}$}

aDepartment of Pharmaceutics and Pharmaceutical Technology, Faculty of Pharmacy, Universitas Padjadjaran, Jl. Raya BandungSumedang Km. 21. Indonesia, bDepartment of Pharmacy, STIKes Bakti Tunas Husada, Tasikmalaya, Indonesia, cIndonesia School of Pharmacy, JI Soekarno Hatta no.354, Bandung, Indonesia

Email: arif.budiman@unpad.ac.id

Received: 03 Dec 2020, Revised and Accepted: 09 Jan 2021

\section{ABSTRACT}

Objective: The aims of this study were to formulate gel from Gynura segetum (GS) extract and evaluate its burn-healing activity.

Methods: GS extract was formulated using carbomer and carboxymethylcellulose (CMC) as a stabilizer with various concentrations. Furthermore, the gel of GS extract was evaluated, including organoleptic, $\mathrm{pH}$ and viscosity. A burn-healing evaluation was conducted by making a wound with a hot plate on male Wistar rats, and $600 \mathrm{mg}$ of the gel was applied. Subsequently, the presence of erythema and width contraction of the burns were observed for $15 \mathrm{~d}$.

Results: The result showed that the formulation containing $1 \%$ of carbomer and $1.2 \%$ of GS extract has the best physical stability. The gel also increased the rate of the healing process with decreased burn wound contraction (5.67 mm after $15 \mathrm{~d}$ ) and the erythema than the control ( $8.50 \mathrm{~mm}$ after $15 \mathrm{~d}$ ). The significance value was less than 0.05 , indicating that the rate of the healing process was significantly different between the GS extract gel and the control.

Conclusion: This finding demonstrated that the gel of GS extract can significantly improve the burns wound healing process and may also be safely used for topical preparation.

Keywords: Gynura segetum, Gel, Burn wound healing, Carbomer

(C) 2021 The Authors. Published by Innovare Academic Sciences Pvt Ltd. This is an open access article under the CC BY license (https://creativecommons.org/licenses/by/4.0/) DOI: https://dx.doi.org/10.22159/ijap.2021v13i2.40438. Journal homepage: https://innovareacademics.in/journals/index.php/ijap

Burn wound is a major health problem due to its incidence of serious complications [1], and it causes infections which have led to 50-75 \% of hospital deaths [2]. The infection can also exacerbate systemic inflammation and delay re-epithelialization due to hypermetabolism and inflammation $[3,4]$ since many synthetic drugs have been used for wound healing. However, due to the occurence of allergy and resistance [5], natural drugs are used as alternative.

Wound healing is the repair process following an injury to the skin or other tissues. Thereafter, an inflammatory response occurs to increase the collagen production by the cells below the dermis and the regeneration of epithelial tissue in the outer skin layer. The process is divided into three steps: inflammation, proliferation, and remodeling [6]. The ultimate goal of burn management is to heal wounds in a short time and prevent infection [7].

Gynura segetum (GS), family Compositae (Asteraceae) is a traditional plant found in the tropical regions of Indonesia and Malaysia [8]. It has been shown to trest cancer, diabetes, inflammation, hypertension, and skin afflictions [9]. Furthermore, the saponin and flavonoid contained in this plant act as anti-inflammation, analgesic, and antiseptic.

Therefore, this study aimed to formulate gel from GS extract to increase the burn wound-healing process, and the activity, as well as the physical stability on storage, were also investigated.

GS was purchased from the Research Institute for Medicinal Plants (BALITRO) Bandung Indonesia and authenticated by the Department of Biology, Faculty of Science, Universitas Padjadjaran, Bandung, Indonesia with specimen no: 236/HB/02. The result of authentication showed that the species of GS used in this research is Gynura segetum (L.) Merr. All other chemicals used in this experiment were of technical grade, and male Wistar rats were obtained from Lembang, West Java, Indonesia.

The phytochemical screening of GS extract was conducted to detect secondary metabolites such as flavonoids, alkaloids, steroids, saponins, terpenoids and tannins [10].

Table 1: Composition of GS extract gel

\begin{tabular}{|c|c|c|c|c|c|c|}
\hline \multirow[t]{2}{*}{ Materials } & \multicolumn{6}{|c|}{ Formula (\%) } \\
\hline & I & II & III & IV & $\mathbf{V}$ & VI \\
\hline Carbomer & 1 & 1.5 & 2 & - & - & - \\
\hline $\mathrm{CMC}$ & - & - & - & 2 & 3 & 4 \\
\hline Gynura segetum & 1.2 & 1.2 & 1.2 & 1.2 & 1.2 & 1.2 \\
\hline Propylene glycol & 10 & 10 & 10 & 10 & 10 & 10 \\
\hline Triethanolamine & q. $s$ & q. $s$ & q. $s$ & - & - & - \\
\hline Propylparaben & 0.02 & 0.02 & 0.02 & 0.02 & 0.02 & 0.02 \\
\hline Methylparaben & 0.18 & 0.18 & 0.18 & 0.18 & 0.18 & 0.18 \\
\hline Sodium EDTA & 0.05 & 0.05 & 0.05 & 0.05 & 0.05 & 0.05 \\
\hline Sodium Metabisulfite & 0.1 & 0.1 & 0.1 & 0.1 & 0.1 & 0.1 \\
\hline Water add & 100 & 100 & 100 & 100 & 100 & 100 \\
\hline
\end{tabular}

The gel formulation from the GS extract was prepared according to the formula shown in table 1. Propylene glycol was admixed with water, and then carbomer and carboxymethylcellulose (CMC) were dispersed into the mixture of glycerine and distilled water, respectively. In addition, GS extract and other components were dissolved in the water and added into the obtained mixture. Triethanolamine (TEA) was also 
added and stirred until homogeneous mass of gel was formed [11]. The physical stability of GS extract gel was evaluated, including organoleptic, $\mathrm{pH}$ and viscosity [12].

The ethical approval for the experimental procedure was obtained from the Health Research Ethics Committee, Universitas Padjadjaran with No: 1291/UN6. C1.3.2/KEPK/PN/2016. The Male Wistar rats obtained from Lembang, West Java, Indonesia, were acclimated to laboratories conditions for $7 \mathrm{~d}$. The Male Wistar rats were anesthetized by urethane, the hairs were shaved and the underlying skin was cleaned with ethanol. A metal cylinder (diameter $1 \mathrm{~cm}$ ) heated in the water $\left(80^{\circ} \mathrm{C}\right)$ for $1 \mathrm{~m}$ was used to create the burns. The metal cylinder was exposed on the shaved area of the rats for $10 \mathrm{~s}$. After the treatment, the burn-healing process was evaluated by measuring wound contraction and the presence of erythema [13, 14]. The wound surface area was traced on a transparent paper and calculated by the following equation:

$$
\% \text { of wound contraction }=\frac{100\left(A_{o}-A_{t}\right)}{A_{o}}
$$

Where $A_{o}$ is the initial wound and $A_{t}$ is the wound on $t$ day.

These results were analyzed using the one-way analysis of variance (ANOVA) at the level of $(\mathrm{P}<0.05)$ and all data were shown as a mean of samples \pm standard deviation (SD).

Phytochemical screening was conducted to evaluate the secondary metabolite of GS extract and flavonoids, alkaloids, saponin, steroids, polyphenol, mono-and sesquiterpene were observed. Saponin acts as an antimicrobial agent, improving wound contraction and the rate of epithelization [15]. Polyphenol accelerates tissue regeneration and also acts as an antiseptic agent against infection. Furthermore, it is used as an astringent to increase rates of wound contraction and epithelization [16].

CMC, which is similar to other natural polymers, was used in this study due to its cross-linking ability to form hydrogel under suitable conditions [17], while carbomer was used due to its wide use in commercial gel preparations [18]. Propylene glycol was used as a moisturizer and enhancer improving the solubility of the active substance in the stratum corneum and drug diffusion through the skin [19]. In addition, triethanolamine was used to neutralize gels containing carbomer after dispersed into water. The hydrogen bonding and ionization of the carboxyl group occurred in the $\mathrm{pH}$ range 6.0-8.0 leading to gel formation [13]. To prevent gel degradation, methylparaben and propylparaben, ethylenediaminetetraacetic acid (EDTA) and sodium metabisulfite were used as preservatives, chelating agents and antioxidant, respectively [20-22].

The result of $\mathrm{pH}$ measurements of GS extract gel are shown in the following fig.:

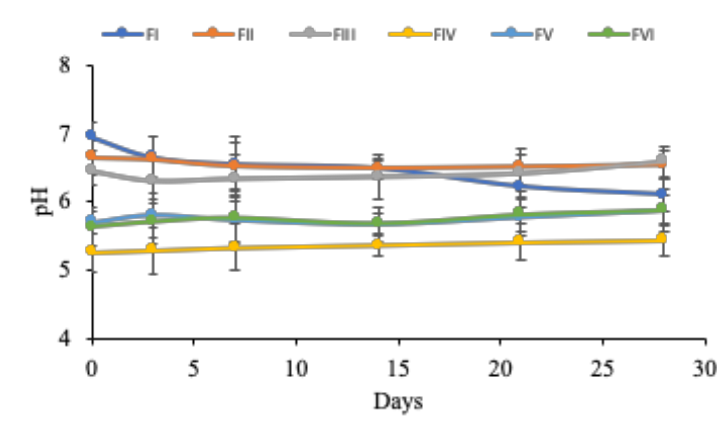

Fig. 1: pH measurement result of GS extract gel (All of the results were calculated as mean \pm standard deviation; $n=3$ )

Base on $\mathrm{pH}$ measurements, GS extract gel still remained within the acceptable value of 4.5-6.5 for topical dosage form. $\mathrm{pH}$ of gel may affect the penetration rate of the preparation, the solubility, and stability of drugs [23]. The value of significance was $0.058(\mathrm{P}<0.05)$, indicating that the difference of $\mathrm{pH}$ during storage was not significant.
The viscosity measurement of GS extract gel after $28 \mathrm{~d}$ storage is shown in fig. 2.

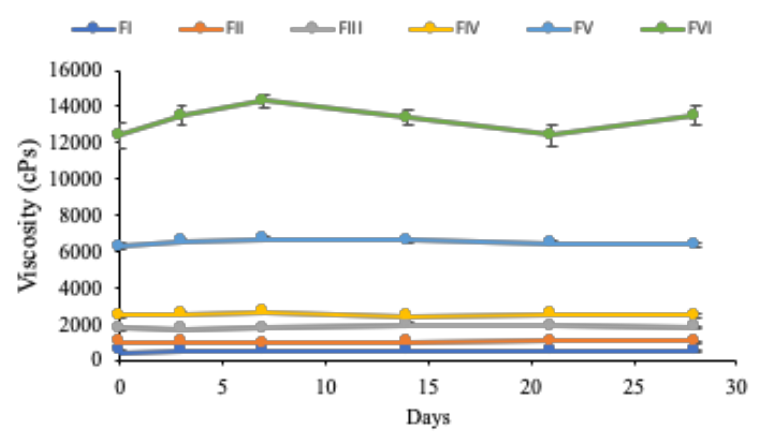

Fig. 2: The result of viscosity measurement of GS extract gel after 28-day storage (All the results were calculated as mean \pm standard deviation; $n=3$ )

The viscosity of GS extract gel increases with both carbomer and CMC. This is in accordance with what was reported according to the previous study, wherw the viscosity of the gel depends on the polymer concentration [24]. The significance value was $0.068(\mathrm{P}<0.05)$, indicating that the difference in gel viscosity during storage was not significant.

The results of wound contraction and erythema score of GS extract gel are shown in the fig. 3 and fig. 4.

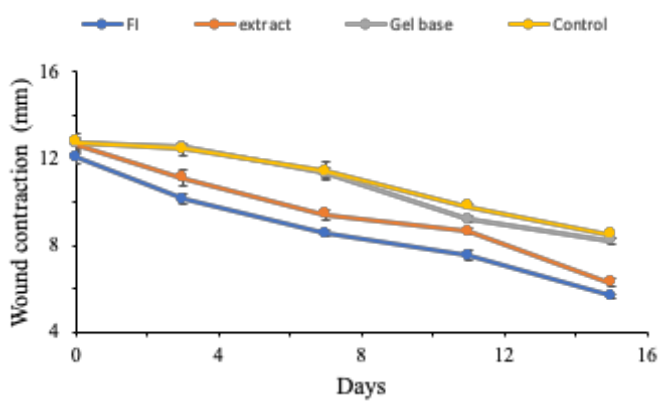

Fig. 3: The result of wound contraction of GS extract gel after 15 d (All the results were calculated as mean \pm standard deviation; $n=3$ )

The wound contraction of GS extract gel after $15 \mathrm{~d}$ was $5.67 \mathrm{~mm}$, while the gel base (without GS extract) and control were 8.22 and $8.50 \mathrm{~mm}$, respectively. The significance value was less than 0.05 , indicating that the wound contraction was significantly different between the GS extract and the control. This result showed that GS extract gel improved the rate of burn healing process.

Furthermore, the observation of erythema can be used as a parameter to study the healing process of gel. The score is calculated by comparing the amount of red color on burn wound with that of healthy skin. Table 2 as reported by Maschekposhtia et al., 2017 [25] shows the erythema score with different levels of redness.

Table 2: Erythema score

\begin{tabular}{ll}
\hline Skin color & Erythema score \\
\hline No color & 0 \\
Slightly pink & 1 \\
Pink & 2 \\
Red & 3 \\
Dark red/purple & 4 \\
\hline
\end{tabular}




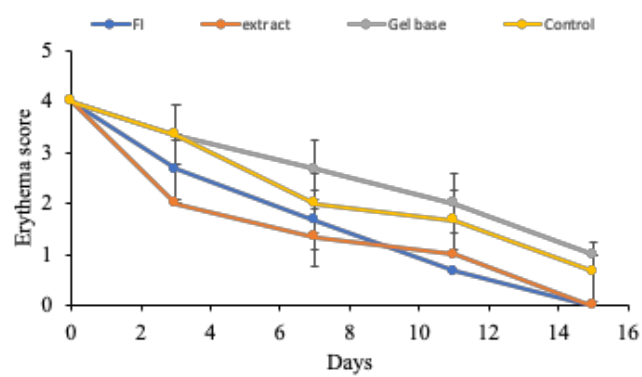

Fig. 4: The result of erythema score of GS extract gel after $15 \mathrm{~d}$ (All the results were calculated as mean \pm standard deviation; $\mathbf{n = 3 )}$

This result showed that GS extract gel reduced the erythema caused by burn wounds. Its saponin content can be attributed to the reduction of inflammation due to decreased erythema [26].

This study examined the activity of GS extract on the burn healing process in gel formulations. The extract was successfully formulated into gel preparation using carbomer and HPMC as stabilizers. In vivo study showed GS extract gel could increase the rate of the wound healing process. This study provides fundamental insight into optimizing the gel formulation of extract as a topical preparation to improve the burn wound healing process.

\section{FUNDING}

Nil

\section{AUTHORS CONTRIBUTIONS}

All the authors have contributed equally.

\section{CONFLICT OF INTERESTS}

Declared none

\section{REFERENCES}

1. Pirbalouti AG, Yousefi M, Nazari H, Karimi I, Koohpayeh A. Evaluation of burn healing properties of Arnebia euchroma and Malva sylvestris. Electron J Biol 2009;5:62-6.

2. Mokaddas E, Rotimi VO, Sanyal SC. In vitro activity of piperacillin/tazobactam versus other broad antibiotics against nosocomial gram-negative pathogens isolated from burn patients. J Chemother 1998;10:208-14.

3. Edgar DW, Fish JS, Gomez M, Wood FM. Local and systemic treatments for acute edema after burn injury: a systematic review of the literature. J Burn Care Res 2011;32:334-47.

4. Sommer K, Sander AL, Albig M, Weber R, Henrich D, Frank J, et $a l$. Delayed wound repair in sepsis is associated with reduced local pro-inflammatory cytokine expression. PloS One 2013;8:e73992.

5. Purna SK, Babu M. Traditional medicine and practices in burn care: need for newer scientific perspectives. Burns 1998;24:387-8.

6. Nayak BS, Pereira LM. Catharanthus roseus flower extract has wound-healing activity in sprague dawley rats. BMC Complement Altern Med 2006;6:1-6.
7. Atiyeh BS, Costagliola M, Hayek SN, Dibo SA. Effect of silver on burn wound infection control and healing: review of the literature. Burns 2007;33:139-48.

8. Seow LJ, Beh HK, Sadikun A, Asmawi MZ. Preliminary phytochemical and physicochemical characterization of Gynura segetum (Lour) merr. (Compositae) leaf. Trop J Pharm Res 2013;12:777-82.

9. Yuan SQ, Gu GM, Wei TT. Studies on the alkaloids of Gynura segetum (Lour.) Merr. Acta Pharm Sin 1990;25:191-7.

10. Budiman A, Rusnawan DW, Yuliana A. Antibacterial activity of Piper betle L. extract in cream dosage forms against Staphylococcus aureus and Propionibacterium acne. J Pharm Sci Res 2018;10:493-6.

11. Islam MT, Rodriguez Hornedo N, Ciotti S, Ackermann C. Rheological characterization of topical carbomer gels neutralized to different pH. Pharm Res 2004;21:1192-9.

12. Budiman A, Praditasari A, Rahayu D, Aulifa DL. Formulation of antioxidant gel from black mulberry fruit extract (Morus nigra L.). J Pharm Bioallied Sci 2019;11:216-22.

13. Djerrou J, Maameri Z, Hamdo Pacha Y, Serakta M, Riachi F, Djaalab $\mathrm{H}$, et al. Effect of virgin fatty oil of Pistacia lentiscus on experimental burn wound's healing in rabbits. Afr J Tradit Complement Altern Med 2010;7:258-63.

14. Shivhare Y, Singour PK, Patil UK, Pawar RS. Wound healing potential of methanolic extract of Trichosanthes dioica Roxb (fruits) in rats. J Ethnopharmacol 2010;127:614-9.

15. Arun M, Satish S, Anima P. Herbal boon for wounds. Int J Pharm Pharm Sci 2013;5:1-2.

16. Tsala DE, Amadou D, Habtemariam S. Natural wound healing and bioactive natural products. Phytopharmacology 2013;4:532-60.

17. Liu P, Zhai M, Li J, Peng J, Wu J. Radiation preparation and swelling behavior of sodium carboxymethyl cellulose hydrogels. Radiat Phys Chem 2002;63:525-8.

18. Islam MT, Rodríguez Hornedo N, Ciotti S, Ackermann C. Fourier transform infrared spectroscopy for the analysis of neutralizercarbomer and surfactant-carbomer interactions in aqueous, hydroalcoholic, and anhydrous gel formulations. AAPS J 2004;6:61-7.

19. Lane ME. Skin penetration enhancers. Int J Pharm 2013;447:12-21.

20. Patil PM, Wankhede SB, Chaudhari PD. Stability-indicating HPTLC method for simultaneous determination of ketoprofen, methyl paraben and propyl paraben in gel formulation. J Pharm Res 2013;6:945-53.

21. Dotto SR, Travassos RMC, De Oliveira EPM, de Lima Machado ME, Martins JL. Evaluation of ethylenediaminetetraacetic acid (EDTA) solution and gel for smear layer removal. Aust Endod J 2007;33:62-5

22. Maia AM, Baby AR, Pinto CA, Yasaka WJ, Suenaga E, Kaneko TM, et al. Influence of sodium metabisulfite and glutathione on the stability of vitamin $\mathrm{C}$ in $\mathrm{O} / \mathrm{W}$ emulsion and extemporaneous aqueous gel. Int J Pharm 2006;322:130-5.

23. Jyothi D, Koland M. Formulation and evaluation of an herbal anti-inflammatory gel containing Trigonella foenum greacum seed extract. Int J Pharm Pharm Sci 2016;8:41-4.

24. Pednekar A, Dandagi P, Gadad A, Mastiholimath V. Formulation and characterization of meloxicam loaded emulgel for topical application. Int J Pharm Pharm Sci 2015;7:216-22.

25. Machekposhtia SA, Soltani M, Raahemifarc K. PASI area and erythema scoring using YIQ color space. Dermatol Res Skin Care 2017;1:8-14

26. Budiman A, Khoerunnisa R, Qoriah TA. Wound-healing test of Piper betle leaf extract and aloe vera in gel preparation. Int J Appl Pharm 2018;10:86-91. 